of commonplace theory, bat may be sharply contrasted with both one and the other. It will not be in the strict sense mystical, but it will certainly be obnoxious in the popular judgment to the reproaches which are justly levelled at mysticism, and it will only escape from them to fall in to the condemnation of an absolute destructive scepticism. The three great men whose minds I have taken as typical of true philosophic genius-Plato, Spinoza, Hegel-were the shrewdest, sternest, hardest-headed of scientific thinkers. And it is certain that any true follower of a transformational theory will in the degree permitted by bis powers present the same destructive aspect to the eye of the votary of the given. What then is the secret of the union, in each of these cases, of an element akin to mysticism and often mistaken for superstition with a criticism to which nothing seems sacred? It is simply the old story, that anyone who bolds two ideas together, not side by side, but traly crganised and in anity, appears to the man in the street to be denying both of them. The criticism and the mysticism are not chance tendencies of individual intellects, bat are the negative and positive nspect of the systematic grasp and effort which constitutes true philosophy. It is critical because it rests in no form nor element as ultinate; it is mystical to the common apprehension because in every form or element it grasps to some extent a reality greater than the appearance. To maintain, however humbly, such an attitude as this, is, in my belief, the daty and destiny of philosophy, and, if so, it is plain that we are only at the beyinning, and also that every age of the world will bring new material to our conception of reality. The essential work of the philosopher will be in the future, as it has been in the past, to rise above all that is given; and the outlook is hopeful in this sense, that there is no fear of the task not proving sufficient for the philosopher, though there is considerable doubt whether most philosophers will prove sufficient for the task.

\title{
ON THE LOGICAL MEANING OF PROPER NAMES.
}

By E. C. Benecke.

THE opinions of Logicians are strangely divided as to the value of that doctrine of the Connotation of Names which owes so much to the teaching of Mill. While Dr. Venn, for example, holds that the distinction which it introduces is " perhaps the most valuable distinction for purposes of incellectnal prost to be found within the field of Common Logic,"* for Mr. Bradley, on the other band, it is one 
of those superstitions which he set himself with so much vigour to expose and to demolish in his Principles of Logic. The terms "denotation" and "connotation," he tells us, "serve no useful purpose in logic. They are unnecessary and objectionable" (p. 156), and the indiscriminate nse of the word "connotation" may even expose the user to the dreadfal charge of being a "superior person" (loc. cit.). The best that the logician can do is to "dismiss for ever the term 'connotation,' and try to keep clear of the errors it beacons" (p. 157).

I do not intend to consider the general valne of the theory in the present paper-though I may say in passing that, if one or other of these extreme views must be adopted, I shoold certainly be on the side of Dr. Venn, and that it wonld, in my opinion, be a great pity if logicians generally were to follow Mr. Bradley's advice. But there is no need for me to discuss this here; for, whatever we may think of the appropriateness of the terms as used by Mill, the distinction which they indicate appears (whether as Connotation and Denotation of Names or Terms, or as Intension, Comprehension, or Meaning and Extension of Terms or Ideas, or under some other designation) in crery eystem of Logic (Mr. Bradley's not excepted), and must, therefore, always be of interest to the logician. I shall, therefore, make no excuse for saying a few words on one part of the theory-that dealing with the logical meaning of proper names-as to which there is a difference of opinion among logicians no less remarkable than that as to the general value of the theory.

As to the denotation or extension of the proper name there is, of course, generally no question. The difference arises only as to its connotation or intension.

Mill, as we all know, maintained with some emphasis and consistency that there is no such thing as the connotation of a proper name. Proper names are, according to him, "the only names of objects which connote nothing." * And this is, I believe, the common view. It is maintained, to name only a few eminent examples, by Whately, $\dagger$ by Professor Bain, $\ddagger$ by Dr. Venn, $\S$ by Dr. Keynes, $\|$ and

- Mill, Logic, vol. i, p. 36. My references are to the 4th ed.

+ Whately, Logic, Book II, chap. $\nabla$, sec. 1.

$\ddagger$ Bain, Logic, rol. i, p. 67.

\$ Venn, Empirical Logic, p. 183, seq.

|| Studies in Formal Logic, p. 30. Dr. Keynes, who proposes to distinguish connotation, as the attributcs implied or signified by a name, from intension, as those which are mentally associated with it, whether implied or not, and from comprehension, as the totality of the attributes possessed in common by the class (loc. cit., p. 27), ascribes both intension and comprehension to the proper name, but denies that it has any connocation. 
by nearly all who are, and many who are not,* followers of Mill. + There is, however, obviously something unsatisfactory in having one class of concrete names so entirely different from all the others; aud this must, one would suppose, be particularly annoying to those who hold, with Mill, that the connotation and denotation of concrete names vary, not indeed in inverse ratio, as Hamilton had taught, but yet in some way inversely. If from the names of the highest genera, with maximum of denotation and minimum of connotation, we can descend through a regular series of lower and lower species-names with ever-decreasing denotation and increasing connotation, it is disturbing and spoils the symmetry of the system to come at last to a name whose denotation is restricted to a single individual, but whose connotation, instead of being greuter than that of the species-name next above it, suddenly vanisbes altogether.t $O$ ne would rather expect that, as we have here the minimam of danotation, we should have the maximam of connotation-and accordingly this also has been taught by influential thinkers. Thus Hamilton, e.g., says : "The quantity of comprehension belonging to a notion is the complement of characters which it contains; and this quantity is at its maximam in an individual. The notion of the individual 'Socrates' contains in it, besides a multitude of others, the character's of son of Sophroniscus, Athenian, Greek, Europenn, man, animal, organised being, \&c." § And similarly write De Morgan, $\|$ Jevous, 9 and many others.

This view, however, clearly also bas its serious diffculties.

* Thus, e.g., Mr. Bosanquet, though he bolds the doctrine that a name may be without connotation, to be sbsurd (Logic, vol. i, p. 50), yet speaks of the proper name as, " usually, as such, a mere 'chalk mark,' that mizimum of connotation which is a sine quâ non of denotation" (Essays in Philos. Criticism, ed. by Setl and Haldane, p. 88).

+ Dr. Venn says even that the proper name " has been almost universally understood as an unmeaning mark inposed on an individual for the purpose of distinguishing him," its "express function" being to bar confusion "by drawing a clear distinction between the names which do, and those whici do not, imply attributes" (Empirical Logic, p. 184).

\pm Those who take Mill's view do not hold that this is the case with all names of individuals. Mill himself was careful to distinguiah connotative siogular names from proper aames in this respect (Logic, vol. $i, \mathrm{pp} .34$, seq.), and the same has usually been done by those who adopt his view. As Or. Keynes points out (Studies in Formal Logic, p. 27), it is a mistake, and misleading, to throw the two together in discussing this subject, as is done by Jerons in pp. 2 and 3 of his Studies in Deductive Logic.

$\$$ Humilton, Lectures, vol. ii, p. 220.

I) De Morgan, Formal Logic, p. 228 (chap. xii).

7 Jerons, Elem. Lessons in Logic, 1. 42 ; Principles of Science, p. 27. 
Suppose there were another man who was also a "son of Sophrouiscus, an Athenian, Greek, European, man, animal, organised being," would he on that account be entitled to the name "Socrates"? Clearly not. How many, and which, of the " maltitude of other characters" must he possess to entitle bim to that name? If we are to apply the proper name "Socrates" in this way, then, to use De Morgan's words, the definition by which we decide that "this is Socrates" mnst clearly be "so close as to fit only one man that ever lived";" and if the proper name is to connote all this, its meaning certainly becomes startlingly large. Can a name connote sach a group of attributes that they are all possessed ouly by the one man Socrates? And do we address him as Socrates because he possesses them all? It certainly seems paradoxical to say "yes"; nevertheless I believe that the truth lies on this side, and that it is only by adopting a view approaching this that consistency can be introduced in to logical theory.

Mill's view of the Non-Connotation of Proper Names is put very clearly in the following passages $t:$ " Proper names are not counotative; they denote the individuals who are called by them; but they do not indicate or imply any attributes as belonging to those individuals. When we name a child by the name Paul, or a dog by the name Crsar, these names are simply marks used to enable those individuals to be made subjects of discourse. It may be said, indeed, that we must bave had some reason for giving them those names rather than any otbers; and this is trae; but the name once given becomes independent of the reason. . . . It is no part of the signification of the name .John that the father of the person so called bore the same name; nor even of the name Dartmouth to be situated at the mouth of the Dart. . . . . Proper names are attached to the obiects themselves, and are not dependent on the continuance of any attribute of the object" (p. 34).

"When we predicate of anything its proper name; when we say, pointing to a man, this is Brown or Smith, or pointing to a city, that is York, we do not merely by so doing convey to the hearer any information about them, except that those are their names. By enabling him to identify the individuals, we may connect them with information previously possessed by him; by saying, this is York, we may tell him that it contains the Minster. But this is in virtue of what he bas previously heard concerning York, not by anything inplied in the name. It is otherwise when things are spoken of by connotative names. When we say, the town is built of marble, we 
give the bearer what may be entirely new information, and this merely by the signification of the many-worded connotative name 'built of marble.' Such names are not eigns of the mere objects, invented because we have occasion to think and speak of those objects individually; but signs which accompany an attribute : a kind of livery in which the attribate clothes all objects which are recognised as possessing it. They are not mere marks, but more, that is to say significant marks; and the connotation is what constitutes their signification" (p. 37).

It will not, I presume, be denied by anybody that there is a real difference between proper and general names. We call Mr. Gladstone "Mr. Gladstone" in a different sense from that in which we call him "a man," or even "the Prime Minister of England in 1893." But is the difference that in the one case there is a connotation, in the other there is none?

One thing is clear at the outset. Whether tho name "Mr. Gladstone" has, or has not, a connotation, it certainly does not connote either gladness or the properties of stones. Were it not for the argaments which are always cropping up in discussions on this sabject-as they do, for instance, in the passage just quoted from Mill-it would surely seem superfluons to point out that the connotation of the proper name, if it bas one, has nothing to do with the separate meaning of the words or syllables of which it may be composed, and that such arguments as that proper naxes may become apparently nnsuitable without being changed on that account-that Dartmouth, for example, would continue to be called Dartmouth, though the river should no longer enter tbe sea in the neighbourhood of the town-are therefore quite irrelevant." "Hippopotamus" connotes the properties neither of rivers nor of horses, bat we do not deny that it has a congotation on that account; and just so, if proper names have a connotation at all, "York" and "Williams" will have their connotation on the same grounds and in the same manner as "Dartmouth," " Brown," or "Younghusband."

Another misconception closely allied to the last-named nust also be got out of the way. Mill, it will be remembered, says + : "It may

- The more careful writers do not, indeed, as a ruie lay much stress on these "etymology" arguments; yet they reproduce them. 'Thus even Dr. Venn appears to argue (Empir. Logic, j. 186) that becsuse " the logiciun has nothing to do with the etymology of any tern," and because to him, for example, "the name Brentford no more inplies a ford through the Brent than does Wednesday imply a portion of time which is someliow consecrated to or named after Wodin," therefore proper numes have nothing but denotation. Compare Keynes, Stud, in Formal Logic, p. 39.

+ Logic, loc. cit., p. 34. 
be said, indeed, that we must have bad some reason for giving [to the child or the place the names Paul and Dartmouth] rather than any others; and this is true; bat the name once given becomes independent of the reason. A man may have been named John because that was the name of his father; a town may have been named Dartmonth because it is situated at the mouth of the Dart," and so on. And similar considerations are often brought up in discussions of this question.* But I take it that they have really nothing whatever to do with the question before us. It matters as little to the connotation of his name what reasons may have induced a man's godfathers and godmothers to call him John rather than James or Peter, as it matters to the connotation of the class name what reasons have induced differeut sets of men to call the same class

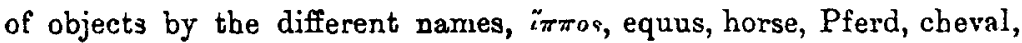
\&c. The connotation is not affected thereby, and the reasons which led to the selection of one name rather than the otber, though of great interest to the philologist, do not in the slightest degree concern the logician in the case either of the general or of the proper name We may, therefore, readily admit that proper names may be given, and that the names of men and women nearly always are given, not to signify the possession of any particular attributes bat quite arbitrarily, and that any other names would do equally well; and we may dismiss that consideration from our thoughts. When, however, the name has been given, it is no longer open to us to call the same man Socrates or Plato at our option; and the question is whether such name, as it is now fixed in denotation, has also become connotative or not. $t$

It is only when it expresses what may be actual thought-that is to say, only when it forms part of propositions-that the meaning of a name or term comes out. It is, therefore, as they appear in propositions that we must study names. Suppose, then, that instead of saying "This is York," I say "This is a city." I am now using an undoubtedly connotative term, and, if my companion did not know the constitution of the group of houses before him, I am giving him, as Mill says, "entirely new information."

What information?

* See, e.g., Venn, Empir. Logic, p. 185, seq.; Keynes, Stud. in Formal Logic, p. 30 ; Bosanquet, Logic, vol. i, pp. 52 , seq.

+ If we say that such names as Strongi'th'arm, Smith, sc., derived any connotation when first given from the fact that the individuals so numed had strong arws, were smiths, \&c., we must admit, with Dr. Keynes, that the names "soon ceased to be connotative" in that sense (Stud. in Formal Logic, p. 30). With what I mean by connotation, however, it is precisely the reverse. That is at its minimum when the name is first given, but rupidly increases. 
Surely the answer must be that that depends on the meaning. which he individually attaches to the word "city." Whether he understands me to have told him that it is "a town, incorporated, which is, or has been, the see of a bishop" (Blackstone), or only that it is "a large collection of houses and inhabitants" (Johnson), or whatever else he understands, will depend on his education and the amount of his knowledge on that particular subject. What, then, is the essential difference between the propositions "This is York," and "This is a city"? If either conveys any information it is sarely by enabling the hearer, in Mill's words, "to connect the object with information previonsly possessed by him," and this in the one case precisely as much as in the other. If be knows that "York is a city," "that it contains the Minster," that this, that, and the other event have happened at York, and that his friend, Mr. S., lives there, then by telling him "This is York" I am telling him all that I should bave told him by saying "This is a city," and a great deal more. Whetber all this, or any part of it, can properly be said to be "connoted" by the name York is, of course, another question; but if there is any good ground for ascribing the information conveyed to connotation in the one case and not in the other, that ground surely does not appear in the reason brought forward by Mill.

True, if my friend had never heard of York before, the informalion given to him by my proposition, "This is York," is not great -nothing more, in fact, than that he may in fature call the object by that name. But how if he had never heard of the word "city"? Do I, in that case, give him any more or any different kind of information by telling him "This is a city" "?

That we cannot make an intelligent use of names without krowing their meanings, and that if proper names have a meaning this must apply to them just as much as to general names, is so self-erident that it seems trifling to insist on it. Yet in discussions on this subject it appears constantly to be dropping out of sight! Thus, Dr. Venn, for example, discasses the amount of information which we could derive from finding in a parish register the entry of the burial of "John Thistlethwaite Barker, farrier," if we knew nothing of any man so named.* We may cheerfully admit that all that we could count on with any confidence would be that given by the last word, "farrier." But quite as little as, or still less than, we can infer from his proper name would be given to us by the fallest description of the man if he had been buried, e.g., in Hungary and the register were made out in Magyar, of which we happened to be ignorant. As our ignorance does not prevent the Magyar words from being 
connotative to those who understand them, just so little does our want of knowledge about John Thistlethwaite Barker prevent the entry of his name in a register from giving information to those who were acquainted with that gentleman.*

In many cases, indeed, we are able to make a guess at at least a portion of the conuotation of a general name whose meaning we do not know. We know, of course, that it is a mere guess, and that if we act upon it we do so at our peril; but we nevertbeless make the guess. For example, if, in an instrument maker's window, I see "Electro Phonometers" advertised for sale, having never either seen or heard of an instrument of this name, I shall not be able to picture to myself the form of the object offered, and shall know nothing of its principle or of its precise purpose and use: but $I$ shall at least guess, with more or less confidence, that it is an instrument, that it can be used in some way to measure sonnds, and that it does this by means of electricity. It is precisely the same with proper names. Suppose that I tell you that at Argamasilla I met Israel Moses, Juan Fernandez, Feinrich Meyer, and Mary Robinson. You know neither the place nor the persons-or, as is also said, you do not know the names. But are you in doubt whether I am speaking of places and persons or of tables and chairs? You will certainly understand, at the very least, that at some place unknown to you I met four human beings of whom I know something, and that of these three were males, one a female. In the present case you will probably be able further to make a pretty confident guess as to the nationality, and even as to the religious belief of some at least of the party. If you do know the place and any of the persons, the information given is, of course, much greater. Now, suppose that, instead of using the proper names given above, I say "At a certain place I met four persons." I am now nuing only names, whose meaning you know. But have I given you more information than before, or less? Surely not more! although in the latter case the words are all connotative, while in the former we are told that they are mere marks destitute of all meaning.

- Mr. Bosanquet (Knowledge and Reality, p. 75) admits that "it is difficult to distinguish such an announzement as 'Mr. Fawcett is dead,' in respect of its significance, from such a sentence as "The Postmaster-General is dead.' But," he adds, "it must be remembered that ordinary proper names hare not the significance that is possessed by those of eminent men."

This, I take it, is only to say that the meaning, or significance, of the names of eminent men is known to more persons than thal of ordinary men. To the nextdoor neighbour of Mr. Hopkins, a tobacconist, there would be just the same difficulty in distinguishing between the significance of the propositions, "Mr. Hopkins is dead," and "The tobacconist next door is dead," as Mr. Bosanquel finds in distinguishing between the two propositions he quotes. 
A man calls his Newfoundland dog "Cæasar." This he does, not to signify that it possesses any particular properties (though he would hardly select that name for a small animal), but simply because the naune pleases him. His little child, learning to speak, hears the dog called, now "Cresar," now "bow-wow." The two names will denote, and raguely connote, to the child precisely the same. A new dog, a Scotch terrier, becomes an inmate of the house. This also is called "bow-wow," but is not called "Cesar." It is called, say, "Scamp." "Bow-wow" will now evidently denote to the child more than either "Cæsar" or "Scamp." Does it connote more? Say that it connotes to him being a "warm, woolly, fourfooted playmate." Surely both "Cæsar" and "Scamp" will also connote all this, and more : the former large size, quiet movements, $\& c$, the latter smaller size, brisker movements, \&c. Shall we say that so soon as the child has learnt so many properties connoted by the name "Cæsar" that it will in that sense apply to no object in the world but one, that name ceases to connote to hirn anytbing at all ?

The name, it would appear, in such a case has not lost but acquired fresh meaning; and $I$ an at a loss to understand why wo should deny to that meaning the name of connotation. It appears to have precisely Mill's characteristics of a connotation. I see an object coming towards me. I say "That is Robinson." Why do I so say? Surely (to use Mill's words) "because the object possesses, and to signify that it possesses, certain attributes." If its attributes were somewhat different, I should not call it "Robinson," but "Brown," or "Smith," or a mastiff, a carriage, or \&c., as the case might be. These attributes, which ure thus proper to Robinson, and not, as a whole group, to other objects, appear then to be what entitle the object in question to the name Robinson, and are, I cannot bat think, connoted by that name.

Such considerations appear to prove, and with a force which is to me irresistible, that the proper name not only does connote but has a very large connotation. But when we ask "What, then, precisely does it connote?" and "What is the real nature of that difference between the proper name and the ordinary general or singular name, which we have already admitted does exist?" it is by no means easy to give an answer.

Perhaps a consideration of a few of the objections to the connotation of proper names may help us towards one.

1. It may be objected that we have no difficulty in transferring a name from one individual to another. Two very different men may both be called Socrates without our being conscious of any impro- 
priety in the application. Innumerable men are called John, and there is no greater likeness or community of properties between all the Johns than between as mauy Johns and James's or Peters. How, then, can "Socrates" or "John" connote any properties?

To this objection, of course, we have a ready answer. The names are simply homonymous in these cases. The proper name of any cine individual is really a different name from that of any other, and it is (from the logical point of view) only an accident, arising from the paucity of names or from other circunstances, that many of these are spelled and prnnounced alike. As a matter of fact, when one first goes to Greece it does sometimes give one a little shock to hear persons called Xenophon, Aristides, Melpomene, \&c., who are very different from those whom one has been used to call by those names: but the fact that such differences exist, and that they almost immediately cease from disturbing or even striking as, no more proves that in each of these cases there is no connotation than the fact that an evening party is different from a child's plaything, and that we have no difficulty in calling both by the same name, proves that there is no connotation to the word "ball." The difficulty, indeed (snch as it is), would not be diminished in the slightest degree by any. amount of similarity between two men called by the same name.

2. It may be objected, again, that the connotation indicates certain properties common to the class denoted by the name: bat how can there be any common properties when the name denotes only one individaal? Here again the answer seems obvious, and the objection indeed little more than a play on words. The common properties of a class of one would appear to be simply the properties of that individual : and if there is a connotation to the name "the present Prime Minister of England," there is not, on that score, any reason against there being a connotation to the name "Lord Rosebery."

As already observed, however, the difference comes out very clearly in sach a case as that last mentioned. When Lord Rosebery resigns his office, the denotation of the former name will change; not so that of the latter: and we shall have to ask hor this difference is related to the respective connotations of the two names.

3. Again it is objected that the proper name cannot be predicated, as it could if it were connotative.

The metaphysical difficnlties in the way of predicating substance do not concern as here, and, from the logical point of view, the answer to this objection is, that it is not true. Mill has already furnished us with instances of the predication of "York," "Brown," and "Swith," and there is no difficulty in finding any number of such cases. 
It is true that the predication of proper names is subject to an important restriction. As a proper name, whether connotative or not, denotes only one object, it is clear that that one object is the only one of which it can be predicated. A proposition with a proper name for its predicate is not, however, on that account necessarily tautologous or unmeaning, like "Socrates is Socrates." The same object may appear, in subject and predicate, under different designations, and the fact that one of these may be predicated of the other-in this case, therefore, that they both denote the same object - may be to the hearer entirely new information. Suppose, for example, that I have asserted some fact as to which you are incredulous. If I say, "My authority is Professor Huxley," I certainly give information-information which may greatly modify jour opinion as to the probability of the fact in question.

None of these objections appears, therefore, to touch the question of the connotation of proper names. But it will have been observed that they all bring out, in one form or the other, the fact that it is of the essence of the proper name to denote only one individual. To distinguish that one individual, whether person, place, or thing, is in fact the frst purpose for which a proper name is given: and this is so completely its prime function that the moment it ceases to distinguish that individual it loses its meaning and becomes a different word.

Any other information it may give, either connotatively or otherwise, is therefore given only secondarily: and we appear thus to have a sufficient ground for the difference between the proper and the singalar name as to which we were inquiring." In the years 1760 and 1784 the singnlar name "The present Prime Minister of England " had different meanings, both denotative and connotative: denotative, because it denoted different individnals; connotative, because the time signified by the word "present" was different, and becanse of all the consequences which that difference of time brought with it. But so by far the larger part of the connotation is identical in the two cases, that there is a sense in which it may be said that the two counotations are the same. The names "Mr. Pitt" had in those years the same difference of denotation. They denoted the same two individuals. And no doubt the names "the present Prime Minister," like the names "Mr. Pitt," were in those years often ased merely to denote the one who was holding the office at the time. But there is this difference: the merely singular name would designate the person meant by drawing attention to his possessing

* The distinction is clearly put by Mr. Bosanquet, Logic, rol. i, p. 51, although, as will be seen, I think he is mistairen as to what is connoted by the proper name. 
the attributes forming the common connotation just referred to. The proper name would effect the same end, not by drawing attention to what was common to the two men (their humanity, nationality, \&c.), but in some more direct manner: and if (as I suppose must have been the case) any of the properties of the Mr. Pitt meant were mentally used for this purpose, they were probably chiefly those in wbich he differed, and by which he was distinguished, both from the other $\mathrm{Mr}$. Pitt and firom other men.

But if so, what does the proper name really connote?

It would appear that the answer must be, that what it connotes to us will depend on what we know about the individual denoted by the name. We bave already seen that if, pointing to a city, I tell you "That is York," the amount of information that I thereby give you depends altogether upon what you know about York. According to your bnowledge, or your ignorance, it may be anything between the mere fact that the place pointed to is called by that name and that it is the city which has played such and such a part in English history and been the scene of such and such events, that it contains the Winster, has so and so many inhabitants, is the see of an archbishop, \&c., \&c., \&c.

Similarly with the names of persons. If I say, for example, "Immanuel Kant was born on the 22nd April, 1724," I may tell one man only that on that day was born a child who was probably the son of a Mr. Kant and who subsequently received the name Immanuel; another will know that the child referred to was a German and afterwards became a well-known philosopher; a third may know that he wrote certain works which produced a revolution in philosophy; a fourth, that he became Professor of Philosophy at Königsberg, that he held this, that, and the other philosophical views, wrote such and such books, had such and snch distinguished pupils and opponents, did and suffered such and such things, died in 1804, \&c., \&c., \&c.

Are we, then, to say that the proper name connotes to each man what he knows, or happens at the time to remember, about the individual denoted by it? If so, we must admit that the connotation of such a name is a very uncertain and varying quantity, and we appear to be landed in a kind of chaos.

This certainly sounds somewhat alarming and as though so fluctuating a connotation could not possibly be of any use, but must lead rather to confusion. We may, however, be somewhat reassured by remembering, in the first place, that if indeed it is so, it does not lead to much practical inconvenience-the difference in different men's knowledge about the man named does not, as a matter of fact, often interfere with their agreenent as to who it is 
that they are talking about: and, in the second place, that we have something similar in the case of general names also.

We have already seen that if, instead of saying "That is York," I say "That is a city," although "city" is admittedly a connotative name, it by no means follows that I shall give to every hearer exactly the same iuformation. On the contrary, the information will vary according to the knowledge of the respective hearers: and if the connotation of the word is always exactly as it is defined, say by Blackstone, we must admit that very many persons use it without knowing its connotation or meaning.

Logic, incieed, is fond of postulating-or of assuming without special notice-that the connotation of its general names is fixed, and that all men use their words in precisely the same sense: and it would undoubtedly be very convenient, not only for the purposes of Logic but also for life in general, if they did so. In the admirable first chapter of his Empirical or Inductive Logic, in which be gives an account of the assumptious which the science, according to his view of it, is obliged to make at the outset, Dr. Venn says, in introducing this postulate:" "In reference to the statement that words must have the same meaning in the minds of all who ase them, one has really some difficulty in insisting upon this as a postulate; for it is at once so absolntely necessary for scientific accuracy, and yet in practice so obviously untrae." $\dagger$ Untrae in practice it most certainily is; and this to so great an extent that we shall ran no great risk in saying that the words as to whose connotation all men are completely in accord are comparatively very few in number: and when we are considering, not the necessities of an abstract science but the real logical meaning of the words we use as the symbols for our thonghts, we are bound not only not to ignore that fact, but to take it into careful consideration.+

* Empir. Logic, p. 37.

† Similarly Dr. Keynes observes (Studies in Formal Logic, p. 31-2): "It has to be borne in mind thal as a matter of fact different people may by the same name mean to imply different things, that is, that attributes thes would include in the connotation of the name would be different; and not unfrequently some of us may be unable to say precisely what is the weaning that we ourselves attach to the words we use. In Formal Logic, however, we work on the assumption that exery name has a fixed and definite connotation. . . . . It map be observed that in the case of an ideal language, every name would hare the same fixed and precise meaning for every one."

$\ddagger$ I need hardly say that throughout the same logical operation the meanings of our words must of course remain absolutely the same. This is a postulate of common thought no less than of Formal Logic, and is expressed by the Laws of Identity and of Contradiction as fundamental laws of thought. Uniess "A is $A$ " is true, and " $A$ is not $A$ " is false, all thought is impossible. 
How it comes about that general names can do their work and that men are able to communicate with one azother by their means without the greatest confusion if their denotation is fixed by the connotation, aud it the connotation is thus different for one man from what it is for another. I cannot, indeed, consider in the present paper. I must content myself with pointing to the fact that the problem exists : that practically it solves itself--probably mainly by the mutually corrective action of connotation and denotation; and that it is in reality only a part of the larger problem, how it is possible that all the different " real worlds" as they must appear in the minds of the several human observers, should harmonise in the ranner in which we find that as a matter of fact they do. If each one of us has to form his own "world" out of the elements furnished to him by his experience," and if these elements can hardly be throughout completely the same in any two cases, it will follow that the "world of meanings "-the significance of those spmbols by which he represents the objects of his world-must be, at least to a very great extent, different in the case of any one individual from what it is in that of any other. $t$ This is surely a fact of great importance for practical logic, and it is a pity if the exigencies of any particular trentment of the science oblige logicians to leave it out of sight. As regards the connotation of names, I am convinced that the habit of ignoring such differences and of speaking as if the connotation were fixed once for all and were the same for all men, greatly diminishes that "intellectual profit" which Dr. Venn so truly says may be derived from the stady of the theory of the import of names.t Indeed I should not be surprised if the unreality which it introduces into the science were one of the causes of the low estimation in wbich Logic, and particularly Formal Logic, is nnfortunately so often held.§

But however this may be, it is admitted on all hands that practically our language is still very far from that ideal state in which "every name would have the same fixed and precise meaning for

"The term " experience" must of course be taken in a wide sense, to include his special education, his intercourse with his fellow men, dc.

† This is well brought out by Mr. Bosanquet, Logic, Introd., sec. 7 , roi. i, pp. 41, seq., cf. p. 82, \&c.

\pm Empir. Logic, p. 173.

$\S$ If, as Mill suggests (Logic, rol. 1, p. 32), the connotation of "man" is " corporeity, rationality, unimal life, and a certain external form, which for distinction we call the luuman"-and this is a much fuller connotation than is allowed by some logicians-then according to logic, when we predicate "man," we assert the possession of those attributes, neither more nor less. But we all feel that we mean to say a great deal more of an object when we call it "a man," and we are nnnoyed at the science which, by fixing the above as the connotation, appesis to assert the contrary. 
everyone" (Keynes); and if the connotation of many general names thus varies so greatly from individaal to individual, we need not be surprised if the same is the case with proper names also.

Returning, then, to the question, What does a proper name connote? I must say in the first place-

(1) That by the connotation of a proper name I do not mean that kind of general meaning wbich some proper names acquire "when they are used to designate i certain type of persons; for exanple, a Diogenes, a Thomas, a Don Quixote, a Paul Pry, a Benedick, a Socrates." Everyone will agree with Dr. Keynes that "when so used such names have really ceased to be proper names at all; they have come to possess all the characteristics of general names." *

Nor (2) do I mean anything that we can predicate of all the objects that happen to be called by some particalar proper name. We may readily agree with Miss Jones that " of all the objects called John Smith we can only predicate (1) what is common to all subjects; (2) unique individuality; (3) a distinctive name; (4) what that name is (i.e., John Smith)"; $\dagger$ but this does not at all affect my question. I bave already observed that, in the sense in which I speak of it in this paper, "John Smith" is a different name as applied to each different individual, and I have therefore nothing to do with looking for properties common to all those who are so named. If we were to look for the properties that we can predicate of all objects called by such general names as " ball," or "cricket," our list would not be much longer or more important than in the case of "John Smith."

What I do mean by the connotation of a proper name is, all those properties, characteristics, or whatever else you like to call them, which the speaker or the bearer takes to be so implied when we call any object by its proper name, that if any of them cannot truly be predicated of the object in question, the proper name is not properly applied to it in the sense in which it is used.

Now if we so nnderstand it, the connotation of, for example, a man's proper name will extend, for each of us, to ever'y most trivial circumstance connected with him of which we happen to be aware. So far as our knowledge extends, it will comprise every property he possesses, every event in his life, + every detail of his personal

- Kejnes, Studies in Formal Logic, p. 30 ; cf. Bosanquet, Logic, vol. i, p. 51, \&c.; also the same author's Essay on "Logic as the Science of Knowledge," in Essays in Philos. Criticism, ed. by Seth and Haldane, p. 88.

+ E. E. C. Jones, Introd. to General Logic, p. 7. As a matter of fact I think we might probably predicate rather more of them, viz., humanity, \&c. But this is doubtful. There may be ships, \&c., so called.

† That is to say, the fact of its having occurred to him. 
appearance at different periods of his life, \&c., \&c., \&c. It sonnds absurd to say that the name can connote all this, or even to speak of a connotation at all if what we mean is such a miscellaneous group of properties and circumstances, which varies so greatly not only between man and mas but in the same man from time to time.* But consider the circumstances :

Suppose that someone with whom you are conversing, mentions the name "Kant." You take it for granted that be is referring to the Königsberg philosopher, but it presently appears that the man he is speaking of, neither was a philosopher nor resided at Königsberg. You therefore know at once that this is not the Kant of whom you were thinking, that is to say, that the name "Kant" in the sense in which you had understood it, is not applicable to bim: and if the contention of this paper is at all correct " baving been a philosopher and resided at Königsberg" must be connoted by the name "Kant" in the sense in which you had understood it.

But if we admit this, we must at once go a great deal further. If you know, for example, that the Kant you mean was born in 1724, and was so regular in his habits that he took the same walk at exactly the same hour every day during many years of his life, then jou will hare to deny the name "Kant" (as the name of that philosopber) to anyone who was not born in that year, or who had never been in the habit of taking such regular walks, and these characteristics will therefore, by the same reasoning, be connoted by the name. If, for example, you would unhesitatingly say that an opinion discussed, say, in a work published in 1730, was not first put

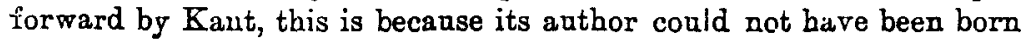
so late as 1724, and therefore could not have been "Kant"; that is to say, to call him Kant is to assert that he was born in that year. And similarly with every characteristic, every event, everything of any kind which we know to be true of Kant. If we once admit any one of them-i.e., if we allow that there is any connotation at all-I do not see how we can exclude any other. It must be all or none. And as I have already explained that in my opinion there is and must be a connotation-as, indeed, the doctrine that any concrete name can be without a connotation is unintelligible to meI am forced to take the latter alternative, that the connotation really does embrace them all.

But we must, I think, go further still. The proper name applies,

* It is hardly necessary to observe that, in this sense, the connotation to me of the name Kant, for example, will be very different just after I have read a biography of that philosopher, or have been studying any of his works, than it was just before, or will be in a year or two. 
and is meant to apply, in the same sense to one indiridual mly; and (anless we will give $\mathrm{pp}$ the principle that in connotative names connotation and denotation determine one another) this fact also must, it appears to me, be included in its connotation. I cannot agree with De Morgan," that the fact "that there was only one Julius Cæesar . . . . and that our definition of Cæsar is so close as to fit only one man that ever lived, makes no essential difference in the character of the proposition ['Julius Cæsar was a Roraan ']," or that such a proposition "is only objectively singular but ideally plural" (loc. cit.). On the contrary, when I call Julins Casar by his proper name, I draw particular attention to the fact that I am speaking of one particular man-the man whom we know as the conqueror of Gaal, \&c., \&c.- -and that it is of that individaal that I am asserting whatever I now predicate of him. As already observed, it is the fact that this individuality of application is included in the meaning (connotation) of the proper name that makes the essential difference between the proper name and any other kind of singular name (such as "the great Roman stutesman who was murdered on the Ides of March in the year 44 B.c.").

I must apologise for baving dwelt with what I fear will be regarded as tedious insistence apon a matter which may appear to be of comparatively little importance. My excuse must be, in the first place, that the theory of the meaning of proper names is closely connected with that of general names, and so is of no small importance to logical theory in general; and in the second place, that nearly all the logicians with whom I am generally most in accord, take what I believe to be the wrong side on this quetion, so that $I$ was anxious to put what appears to me to be the correct view as clearly as possible. It would be presumptnous in me to go against such a body of opinion if there were not, as I have mentioned, eminent logical anthorities on the other side also. And, appearances and the anthority of logicians to the contrary notwithstanding, I cannot think that (apart, from express theory) the general opinion is really agrainst us. For example, when Mr. Bosanquet asks, $\dagger$ with reference to the proposition "Cæsar crossed the Rubicou," "Where is the significance of crossing the Rabicon, if we do not affirm it. of the conqueror of Gaul, the rival of Pompey, and the true founder of the Roman monarchy?" What is this but to say that by calling the subject of the proposition "Crsar," we assert him to have been the conqueror of Gaul, the rival of Pompey, and the true founder of the Roman monarchy-i.e., that all these things, 
and if so also many more, are connoted by the name "Cæsar," when it refers to him ?*

So also, I think, few persons will deny that if I say, e.g., "the principal speaker was Mr. Gladstone," I am giving you, not less but more information about the speaker in question, than if, instead of "Mr. Gladstone," I say either "a member of Parliament," or "an eminent man," or "a statesman," or "a Liberal leader." It will be admitted that the predicate "Mr. Gladstone," tells us all that is told us by all these other connotative predicates put together, and more : and, if so, I cannot see how it can be denied that it also commotes more.

\section{THE RATIONALITY OF HEDONISM.}

By Miss E. E. Constance Jones.

What I desire to defend in this paper is the ethical doctrine that the proper end of Human Action is the promotion of Happiness, that " the conduct which, under any given circumstances is objectively right, is that which will produce the greatest amonnt of happiness on the whole" (Methods of Ethics, Book IV, Chapter I). It is a doctrine of what ought to be done, not of what merely has been or is or will be in human action; it implies a standard with which the actual has to be compared, and by which it must be judged. No doubt what ought to be is limited by what is possible; no doubt also what ought to be in some sense is; but of everything of which we can speak we may say that in some sense it is, and equally we may say, perhaps, that in some sense it is not-all depends upon the particular kind of existence which is meant. But if by is we mean existent as human conduct, then I do not see how is can be resolved into ought, though it may be coincident with it-in logical phrase, connotation mnst remain different though denotation may be identical. Of course, as far as men act rightly, denotation of is anc? ought is actually coincident.

Perhaps, in a sense, everything is good, everything is true, every-

* As the same writer elsewhere say" ("On the Importance of a True Theory of Identity," in Mind, rol. xiii, p. 358) : "In order to give this judgment its fuli meaning we nust not try to cut it down ... . reducing Cæasar to mean merely a creature that crossed the Rubicon. . . . Precisely the point of the judgnent is that the same man uniled in himself . . . say the relations of being the conqueror of Gaul, and of marching into Italy." "Casar" thus means these and othcr "differences in identity"; and it can do this only by what I call connoting them. 